\title{
Necropolítica tropical em tempos pró-Bolsonaro: desafios contemporâneos de combate aos crimes de ódio LGBTfóbicos
}

\author{
Tropical necropolitics in pro-Bolsonaro times: contemporary challenges \\ to combat LGBTphobic hate crimes
}

\author{
Necropolítica tropical en tiempos pro-Bolsonaro: desafíos \\ contemporáneos de combate a los crímenes de odio LGBTfóbicos
}

\author{
Ettore Stefani Medeiros ${ }^{1, a}$ \\ ettoremedeiros@gmail.com | https://orcid.org/oooo-00o2-6880-3331 \\ ${ }^{1}$ Universidade Federal de Minas Gerais. Belo Horizonte, MG, Brasil. \\ a Mestrado em Comunicação e Sociabilidade Contemporânea pela Universidade Federal de Minas Gerais.
}

\section{Resumo}

Em tempos conservadores pró-Bolsonaro, minorias sociais têm sido alvo de agressões de diferentes ordens, sendo vistas como corpos matáveis, simbolicamente ou não. A partir desse cenário, o objetivo deste trabalho é compreender em que medida há uma rede de cumplicidade que fomenta a manifestação de crimes de ódio LGBTfóbicos na contemporaneidade política brasileira. Para situar o fenômeno teórica e metodologicamente, acionamos o conceito de necropolítica, política de morte que decide quem tem o direito de matar e o de viver. Propomos também a dilatação do conceito de crime de ódio, compreendendo como a morte pode se manifestar para além do óbito, como no controle das subjetividades.

Palavras-chave: Crime de ódio; LGBT; LGBTfobia; Necropolítica; Bolsonaro.

\begin{abstract}
In pro-Bolsonaro conservative times, social minorities have been targeted by assaults of different orders, being seen as killable bodies, symbolically or not. From this scenario, the aim of this article is to understand to what extent there is a network of complicity that foments the manifestation of LGBTphobic hate crimes in Brazilian political contemporaneity. To situate the phenomenon theoretically and methodologically, we trigger the concept of necropolitics, a policy of death that decides who has the right to kill and to live.
\end{abstract}


We also propose the expansion of the concept of hate crime, understanding how death can be manifested beyond itself, as in the control of subjectivities.

Keywords: Hate crime; LGBT; LGBTphobia; Necropolitics; Bolsonaro.

\section{Resumen}

En tiempos conservadores pro-Bolsonaro, las minorías sociales han sido objeto de agresiones de diferentes órdenes, siendo vistas como cuerpos matables, simbólicamente o no. A partir de este escenario, el objetivo de este trabajo es comprender en qué medida hay una red de complicidad que fomenta la manifestación de crímenes de odio LGBTfóbicos en la contemporaneidad política brasileña. Para situar el fenómeno teórico y metodológicamente, accionamos el concepto de necropolítica, política de muerte que decide quién tiene el derecho de matar y el de vivir. Proponemos también la dilatación del concepto de crimen de odio, comprendiendo cómo la muerte puede manifestarse más allá del óbito, como en el control de las subjetividades.

Palabras clave: Crímenes de ódio; LGBT; LGBTfobia; Necropolítica; Bolsonaro.

Este texto compõe o dossiê 40 anos do movimento LGBT no Brasil: comunicação, saúde e direitos humanos.

Contribuição dos autores: o autor é responsável por todo o texto.

Declaração de conflito de interesses: não há.

Fontes de financiamento: bolsa de doutorado Capes.

Considerações éticas: não há.

Agradecimentos/Contribuições adicionais: não há.

Histórico do artigo: submetido: 09 fev. 2019 | aceito: 10 maio 2019 | publicado: 28 jun. 2019.

Apresentação anterior: não houve.

Licença CC BY-NC atribuição não comercial. Com essa licença é permitido acessar, baixar (download), copiar, imprimir, compartilhar, reutilizar e distribuir os artigos, desde que para uso não comercial e com a citação da fonte, conferindo os devidos créditos de autoria e menção à Reciis. Nesses casos, nenhuma permissão é necessária por parte dos autores ou dos editores. 


\section{Introdução}

A presença e a valorização de governos de extrema direita têm se manifestado mundialmente, como pode ser observado nos Estados Unidos, Itália, Filipinas, Turquia e, mais recentemente, Brasil. Nas últimas eleições presidenciais deste país, que ocorreram em outubro de 2018, saiu vencedor Jair Bolsonaro, político do Partido Social Liberal (PSL) conhecido polemicamente por suas posturas conservadoras e por suas declarações misóginas, racistas e envoltas por práticas de ódio direcionadas ao grupo formado por pessoas lésbicas, gays, bissexuais, transexuais, transgêneros e travestis (LGBTfobia).

Durante a carreira política de Bolsonaro, há um extenso rol de falas polêmicas e agressivas, as quais ferem a igualdade social, atacam a democracia e desrespeitam minorias sociais. 'Minoria social' é entendida neste artigo como uma voz qualitativa que envolve a ação social, ética e política de um grupo que, movido por um impulso, visa conquistar reconhecimentos identitários, transformar relações desiguais e reivindicar sua presença nas decisões de poder. Por essa perspectiva, o grupo é visto menos como quantitativamente definido e mais pela sua identificação social e pela vulnerabilidade jurídico-social compartilhada entre seus membros ${ }^{1}$. Dentre as falas ditas por Bolsonaro, citamos algumas a seguir, muitas das quais não foram amplamente levadas em consideração até que ele, de fato, aparecesse como favorito nas pesquisas eleitorais presidenciais. "Eu jamais ia estuprar você porque você não merece [frase dita à deputada Maria do Rosário no Congresso]"2. "O erro da ditadura foi torturar e não matar"3. "Foram quatro homens [que tive como filhos]. A quinta eu dei uma fraquejada, e veio uma mulher"4. "Eu fui num quilombo em Eldorado Paulista. Olha, o afrodescendente mais leve lá pesava sete arrobas. Não fazem nada! Eu acho que nem para procriador ele serve mais"`. "Esses marginais vermelhos [referência a pessoas ligadas ao Partido dos Trabalhadores (PT)] serão banidos de nossa pátria”.

Quando o assunto é a população LGBT, Bolsonaro tampouco deixa de manifestar dizeres controversos. Ao dissertar sobre o projeto kit anti-homofobia nas escolas, o político expressou que "[e]sses gays e lésbicas querem que nós, a maioria, entubemos como exemplo de comportamento a sua promiscuidade" prefere que um filho seu "morra num acidente do que apareça com um bigodudo por aí. Para mim ele vai ter morrido mesmo". Quando a união estável entre homossexuais foi aprovada, esbravejou ironicamente que "[o] próximo passo será a adoção de crianças por casais homossexuais e a legalização da pedofilia" ${ }^{\text {. }}$

Podemos refletir sobre uma infinidade de motivos que levaram a ascensão de Bolsonaro à solução nacional, como a falta de crença e confiança políticas nos partidos e coligações que estiveram por anos no Poder Executivo, o desenvolvimento do antipetismo, a revolta com a corrupção, o descontentamento com a crise econômica e os altos índices de criminalidade. Um motivo, no entanto, nos chama a atenção: Bolsonaro incorpora um tipo de conservadorismo encontrado em várias fatias da população brasileira, que visa à manutenção de privilégios de gênero, sexualidade, raça e classe aos já privilegiados e à revogação de direitos conquistados por minorias sociais. Ao dizer sem pudores as frases supracitadas, Bolsonaro mostra quais vidas importam para ele, legitimando hierarquias em que pessoas negras, mulheres, LGBTs, indígenas, apoiadoras de partidos de esquerda e muitas outras são colocadas em grau de inferioridade.

Se esse foi o presidente eleito no Brasil é porque muitos são os brasileiros que compactuam com seus discursos e práticas. Mais que isso, ter um presidente com esses discursos e práticas permite que a população se sinta à vontade para agir da mesma forma. Prova disso espelha-se em dezenas de crimes direcionados a minorias sociais nos tempos eleitorais brasileiros, entre setembro e novembro de 2018, cujos agressores violentaram simbólica e/ou fisicamente vítimas ao mesmo tempo que revelaram apoio a Bolsonaro, como será mostrado na próxima seção deste artigo.

Consideramos que tais casos podem ser enquadrados enquanto crimes de ódio. Ao tratarmos deste conceito, ancoramo-nos na perspectiva ${ }^{10}$ que concebe que esse tipo de crime não é direcionado a uma pessoa específica, mas destinado a um grupo tido socialmente como inferior, seja por sua nacionalidade, sua religião, seu gênero, sua raça ou sua sexualidade. Nesse sentido, torturas, agressões e assassinatos cujos alvos 
são minorias sociais têm por finalidade não apenas atingirem um corpo, mas aterrorizarem determinado conjunto de pessoas com características comuns e deixar uma espécie de aviso de que suas vidas valem menos. Sobre isso, nos casos de crimes de ódio LGBTfóbicos, relatório ${ }^{11}$ demonstra que a violência aplicada às vítimas é muito superior à mínima necessária para levar um corpo ao óbito, de tal forma que requintes de crueldade se manifestam em inúmeros golpes, facadas e tiros.

Compreendem-se crimes de ódio para além de sua dimensão legal e jurídica ${ }^{10}$. Ainda que importante, essa dimensão não parece ser suficiente para dar conta da problemática envolvendo práticas de ódio como as citadas anteriormente. Como expõe Mendonça ${ }^{12}$, mesmo que questões legais e jurídicas mudem no decorrer do tempo e estimulem que ações preconceituosas e criminosas sejam julgadas e punidas, normas e regras construídas em torno de convenções continuam a operar. É por essa razão que vale dilatar o conceito de crime de ódio e pensar como há uma rede de cumplicidade que o impulsiona, como debateremos adiante.

O ódio LGBTfóbico, além de relacionar-se à desvalorização de minorias sociais, insere-se em um contexto sociocultural de heterocisnormatividade ${ }^{13}$, que hierarquiza os corpos entre aqueles que são vistos como normais e aqueles que são tidos como anormais. Pessoas que possuem identidades ou práticas que escapam à heterossexualidade e à cisgeneridade (termo que se refere às pessoas cuja identidade de gênero corresponde, a partir de normas sociais, ao sexo biológico que lhes foi atribuído) seriam, por essa perspectiva, dissonantes. A heteronormatividade se articula também às convenções de gênero e sexualidade, que tem como características desiguais a superioridade masculina e a subordinação daqueles compreendidos como não masculinos ${ }^{14}$.

Na atual conjuntura política, marcada pela violência às minorias sociais, como a população LGBT, é preciso refletir sobre novas formas de existir e resistir. Buscar (re)conhecimento no passado nacional para compreender formas de mobilização no presente e projetar futuros mais igualitários é um passo que nós, LGBTs, devemos dar enquanto grupo e movimento, seja no cotidiano, na militância e/ou na esfera acadêmica. Levando tal discussão em conta, o objetivo deste trabalho é compreender em que medida há uma rede de cumplicidade que fomenta a manifestação de crimes de ódio LGBTfóbicos na contemporaneidade política brasileira.

A fim de situar esse fenômeno teórica e metodologicamente, propomos o diálogo entre as noções de soberania e biopolítica de Foucault, necropolítica de Mbembe, necropolítica tropical de Pelbart e precariedade de Butler. Com isso, nossa intenção é analisar em que medida o direito de matar e o direito de viver são articulados na contemporaneidade política brasileira, cujo controle dos corpos se dá por estratégias de soberania e biopoder. Em torno dos corpos, constrói-se uma divisão política entre aqueles que podem ou não morrer, já que alguns são tidos como descartáveis ou vidas que não merecem o enlutamento. Nesse sentido, embora todas as pessoas tenham vidas precárias, algumas não passam por esse tipo de reconhecimento. Funcionando a partir da necropolítica tropical, com políticas de morte que têm especificidades brasileiras, crimes de ódio a minorias sociais têm como legado práticas violentas ligadas à colonização e ao regime escravocrata.

\section{Necropolítica tropical: controle da morte e Igbtfobia}

Berenice Bento, em sua fala no III Congresso de Diversidade Sexual e de Gênero de 2018, evidencia que os estudantes negros nas universidades, as mulheres no Congresso, as pessoas trans com seu nome social juridicamente aceito, os casais gays e lésbicos como família legalmente reconhecida incomodam àqueles que sempre tiverem privilégios de gênero, sexualidade, raça e classe exclusivamente para si. As maiorias sociais, pouco dispostas a abdicarem de suas prerrogativas, desejam a permanência das tradições. Bolsonaro representa para elas, em alguma medida, a salvação da moral, da civilidade, dos bons costumes, dos valores verdadeiramente cristãos e, evidentemente, das desigualdades sociais. 
Prova disso espelha-se em dezenas de crimes direcionados a minorias sociais nos tempos eleitorais brasileiros, entre setembro e novembro de 2018, cujos agressores violentaram simbólica e/ou fisicamente vítimas e revelaram apoio a Bolsonaro.

Foram mais de 150 ataques praticados por intolerância política, muitos dos quais se destinaram a pessoas negras, mulheres e/ou LGBTs. O levantamento é uma iniciativa criada por jornalistas do Ópera Mundi, em que diversos profissionais de imprensa catalogaram de modo colaborativo esse tipo de violência desde $1^{\circ}$ de outubro de 2018, originando o então constantemente atualizado Mapa da Violência.

Em termos de LGBTfobia, variadas violências foram denunciadas durante o período eleitoral. Pichações pró-Bolsonaro em paredes de universidades incitavam a morte de homossexuais ${ }^{15}$. Mulher que estava acompanhada de sua namorada no metrô foi empurrada em direção aos trilhos, ao brado de 'Viva Bolsonaro', por homem que vestia camiseta do então candidato. Grupos de pessoas no metrô cantaram "Ô bicharada, toma cuidado, o Bolsonaro vai matar veado!"”6. Michel Cunha, depois de ser espancado por vários homens que diziam que "Bolsonaro vai matar viado", veio a falecer ${ }^{17}$. Priscila, travesti, foi morta na rua por sujeitos que, durante a agressão, afirmavam que "com Bolsonaro presidente, a caça aos viados vai ser legalizada"18.

A fim de ilustrarmos casos de crimes de ódio LGBTfóbicos, apresentamos dados contidos em dois documentos que elucidam a realidade: 1) Em nível continental, o Violência contra pessoas lésbicas, gays, bissexuais, trans e intersexo nas Américas feito pela Comissão Interamericana de Direitos Humanos ${ }^{11}$ (CIDH) em 2015; 2) Em nível nacional, o População LGBT morta no Brasil feito pelo Grupo Gay da Bahia $^{19}$ (GGB) sobre 2018.

Inicialmente, vale expor as similaridades que atravessam esses relatórios, cuja existência é valiosa no atual cenário de subnotificação de violências contra LGBTs e de falta de dados oficiais sobre o fenômeno. Os relatórios demonstram que os recentes números de crimes de ódio motivados por preconceito às orientações sexuais e identidades de gênero são somente a ponta de um iceberg, como elucida o documento do GGB, na medida em que há falta de medidas eficazes para prevenção, investigação, julgamento e contabilização desses crimes. Isso é explicado por diferentes razões, desde o medo que vítimas têm de sofrer retaliações ao fazerem denúncias até o descaso e o maltrato policial, judicial e estatal para tratar de questões de cunho LGBTfóbico. Por vezes, as próprias autoridades culpam as vítimas e/ou não reconhecem um crime como de ódio, conforme disserta o relatório da CIDH. Nesse documento, estatísticas apontam que o Brasil supera consideravelmente o número de crimes de ódio LGBTfóbicos em comparação a qualquer nação das Américas.

Um elemento destacável dos relatórios é que as pessoas mortas por crimes de ódio LGBTfóbicos aparecem com sinais de crueldade às vítimas. Nesse sentido, constata-se que boa parte das vítimas passou por situações degradantes até padecer, o que inclui apedrejamento, enforcamento, desfiguração do rosto, paulada, espancamento, perfuração pelo corpo, degolamento, tortura, queima do corpo e/ou alto número de golpes, facadas ou tiros, técnicas que chamamos de exercício soberano. Mais que isso, investigações dão a ver humilhações e violências verbais sofridas pelas vítimas durante os atos criminosos.

O relatório do GGB apresenta que 420 LGBTs foram assassinados ou se suicidaram no país em 2018 em decorrência do preconceito. Chegou-se a esse número a partir da coleta não oficial de informação em mídias jornalísticas e/ou mídias sociais digitais, o que significa que a quantidade de mortes pode ser maior. Dos 420 casos, apenas 6\% tiveram o criminoso identificado: há uma grande impunidade no Brasil. Ainda conforme constata o documento: "Apesar de ter-se criado certo pânico nas redes sociais e listas LGBT, no tocante à violência letal, felizmente não se detecta aumento de mortes das minorias sexuais nem durante o tenso período da campanha eleitoral, nem neste primeiro mês do Presidente Bolsonaro: em 2018 a média anual de mortes por mês foi de 35 vítimas, sendo que nos dois primeiros meses do ano, atingiu o pico de 47 e 46 LGBT+ mortos, reduzindo para 27 e 38 nos dois últimos meses após as eleições, diminuição de $17 \%$ entre o início e o fim de 2018. E se compararmos esse primeiro mês do Governo Bolsonaro com os sete últimos meses de janeiro entre 2012-2018, observamos uma média de 
36,8 de mortes, sendo registrados até a data desta publicação, 28 mortes, com uma projeção de 35 óbitos para esse mês de janeiro de 2019, taxa igualmente inferior aos anos anteriores"19.

Tais dados não devem ser vistos como essencialmente positivos, já que revelam um alto número de morte de LGBTs que tiveram suas vidas interrompidas por conta do preconceito. Cada vida dentro desse levantamento importa! Ademais, essas estatísticas podem conter brechas e ser mais drásticas, como o próprio GGB tem expressado, na medida em que se estimam subnotificações.

Embora o preconceito letal seja a manifestação de ódio mais séria, a LGBTfobia é feita não somente de mortes, mas também de outras formas de violência, tanto física quanto simbólica. Durante o primeiro mês de governo Bolsonaro, alguns acontecimentos evidenciam a questão. A população LGBT foi retirada das diretrizes de políticas públicas que compõem o Ministério da Mulher, da Família e dos Direitos Humanos. A nova pasta está sob o comando de Damares Alves, que já proferiu que os gays querem banir a Bíblia do Brasil ${ }^{20}$, que sexo entre pessoas do mesmo sexo é aberração ${ }^{21}$ e que meninos devem usar azul, enquanto meninas, rosa $^{22}$. A entrada de Alves no cenário político coincidiu com a saída de Jean Wyllys, deputado federal reeleito em 2019 que, além de ser declaradamente homossexual, foi um dos principais defensores da pauta LGBT no Congresso. A renúncia ao cargo foi feita em decorrência de crescentes ameaças de morte e discursos de ódio que Wyllys e sua família vinham recebendo, motivadas por LGBTfobia. Por prezar por sua vida, o parlamentar saiu do país, deixando em seu lugar o também militante gay David Miranda.

É curioso pensar como diversos votantes em Bolsonaro saíram e ainda saem em sua defesa quando a temática é o ataque às minorias sociais e, especificamente, aos LGBTs. Afirmaram que, se presidente, ele não iria fazer tudo que disse que faria. Consideram que não é culpa dele que as pessoas estejam matando e violentando em seu nome. Dizem que as mortes e agressões de/a minorias já existiam antes. Esses são argumentos proferidos durante e após o período eleitoral que não atestam como a LGBTfobia é complexa, estrutural e atuante em diferentes esferas sociais. Mais que isso, tais argumentos em alguma medida fazem parte da rede de cumplicidade que permite a propagação da LGBTfobia e dos crimes de ódio ligados a ela.

O violento contexto político atual emerge ao lado de inúmeras comparações com o nazismo, correlação ativada de modo significativo por brasileiros que veem na ascensão e na eleição de Bolsonaro um perigo à democracia nacional. É como se ecoasse entre os cidadãos mais progressistas um aviso de que isso já ocorrera antes. Seguindo em alguma medida esse movimento contemporâneo, Pelbart ${ }^{23}$ promove uma discussão em que expressa que é preciso dar a ver o monstro que insurge.

Ao coletar certas partes do Minha luta - plano operacional de ódio, autoritarismo e efetivação de preconceitos escritos de Hitler - Pelbart propõe que poucos foram os que levaram a sério a obra, que já planejava toda a ação do nazismo antes de sua ocorrência de fato. O livro enumerava direta ou indiretamente algumas estratégias de persuasão política, dentre as quais: 1) aproveitar-se da ausência de crença e de esperança da população como modo de convencimento; 2) unificar diferentes adversários, encarnando-os na figura de um inimigo comum que tem a culpa de todos os males e problemas sociais, o que tornaria seu desmantelamento facilitado; 3) inflamar as emoções do povo; 4) destruir o parlamentarismo e aglomerar a autoridade em torno de um chefe, de modo a promover o encerramento da democracia; 5) estimular a defesa incondicional de uma causa, mesmo que isso leve à intolerância.

Despontam algumas intersecções entre os itens citados e o contexto contemporâneo brasileiro que cinge a figura de Bolsonaro, como a exploração do descontentamento político dos cidadãos para com a esquerda; a demonização do PT como aglomerador de todo o 'mal' da nação, desde a diluição dos valores tradicionais e a propagação da 'ideologia de gênero' até a corrupção e a falta de segurança nacional; práticas de intolerância e violências simbólicas e/ou físicas contra aqueles que destoam das normas sociais e da hegemonia política; evocação da ditadura como solução para os problemas do 
Brasil. Essas são ideias que pareciam estar enterradas, mas que foram retomadas ou, talvez, apenas saíram do estado de incubação.

Apesar das semelhanças, comparações usualmente contêm um quê de impertinência, sobretudo se levarmos em conta que as dimensões espaciais e temporais do nazismo são diferentes das brasileiras atuais. Assim, Pelbart expressa que, mesmo que o ódio aos judeus no nazismo possa ser transferido para o nosso contexto em uma ponte com o ódio a petistas, LGBTs, negros e feministas, há contornos especificamente tupiniquins nesse fenômeno social. É com essa constatação que Pelbart sugere que vivemos uma necropolítica tropical.

Necropolítica é um conceito desenvolvido por $\mathrm{Mbembe}^{24}$, uma política da morte que articula exercícios de soberania e de biopoder, noções fundamentadas por Foucault. A soberania, bastante representativa na Idade Média, incorporava-se à figura de um soberano, visto enquanto divindade, o qual detinha o direito de fazer morrer ou deixar viver seus súditos ${ }^{25}$. Casos esses desrespeitassem a ordem soberana e fossem vistos como perigo, práticas de penalização altamente violentas eram realizadas sobre o corpo dos acusados, o que incluía técnicas de tortura exacerbadas de crueldade. Isso se dava para que as regras do príncipe fossem restabelecidas, o que por consequência indicava a garantida restituição do poder soberano. Os atos agressivos, além de terem por intenção reforçar a hierarquia entre o soberano e os súditos, não eram considerados criminosos, na medida em que o príncipe gozava de uma posição sagrada de exceção: a ele era permitido punir quem descumprisse seus mandatos.

Já o biopoder é uma modalidade de exercício de poder mais amplo, exercido pelos Estados Modernos com fins de controlar grandes populações a partir de ordens biológicas, como a regulamentação das taxas de natalidade, o monitoramento das doenças, a análise de mortalidade. Nessa lógica, os corpos são regrados a partir da gestão de suas vidas de modo não individualizante. Enquanto o poder soberano liga-se a fazer morrer ou deixar viver, o biopoder ancora-se em fazer viver e deixar morrer ${ }^{26}$. Diferentemente da modalidade soberana, que coloca como inimigos aqueles que põem em perigo a ordem do príncipe, o biopoder desenvolve a ideia de que certos grupos ou pessoas podem prejudicar a vida de toda a população, o que justificaria uma purificação da sociedade ${ }^{27}$. Nesse sentido, o biopoder, em comparação com a soberania, possui uma distribuição de mortes mais reticular e menos explícita.

Ambas as modalidades de exercício de poder se cingem ao que Mbembe chama de necropolítica. Essas são políticas de morte que remontam às épocas coloniais e, consequentemente, à escravização, mas que são levadas a fio por Estados Modernos contemporâneos, os quais também se estruturam por lógicas de biopoder.

A fim de retratar as operações de soberania enquanto direito de matar, Mbembe retoma historicamente a escravização e o sistema de colonização. Vistos enquanto 'selvagens', os nativos cujas terras foram colonizadas não possuiriam lógicas racionais de organização, tampouco seriam morais em comparação aos colonizadores. Estes encarnariam uma ideia universal de civilidade e humanidade, já que se ligariam a um Estado modelo de unidade política. Por essa perspectiva, seria impossível estabelecer paz com os nativos, o que daria abertura para o Estado de exceção, em que a ilegalidade absoluta nas colônias seria paradoxalmente autorizada. A morte e o assassinato estariam, pois, permitidos, o que demonstra que a ordem soberana, mesmo em Estados Modernos com exercícios de biopoder, não requer justificativa quanto à sua ação, a incluir os genocídios da população colonizada. Delineia-se aqui uma evidente divisão política entre aqueles que devem viver e aqueles que devem morrer, o que Mbembe associa com o conceito de necropolítica.

Para ilustrar movimentos coloniais na contemporaneidade, Mbembe traz o caso da ocupação atual na região palestina, atravessada por várias instâncias de poder. O Estado aqui se coloca como dotado de um direito divino de existir e, em ações soberanas e violentas, reivindica seu lugar de potência frente a qualquer outra crença da população. As diferenças culturais e locais dos povos que ali se aglomeram são desres- 
peitadas a partir da valorização de um Estado nacional forjado. Nesse ato de governar autoritariamente, os comandantes militares locais estabelecem seus próprios critérios necropolíticos, escolhendo em quem atiram e quem merece viver.

Ancorado em torno dessa discussão de Mbembe, Pelbart busca pensar de que modo há especificidades na necropolítica brasileira, a qual ele chama de tropical e correlaciona com épocas coloniais nacionais. A chegada dos europeus às Américas esteve atrelada à invasão às terras africanas, cuja população era capturada para servir como escrava no oeste mundial. Destituídos de sua humanidade e do controle de seus próprios corpos pelos europeus, africanas/os eram transportadas/os em navios negreiros. Durante a viagem e após os primeiros dias em solo fértil, cerca de 10\% das/os africanas/os morriam. As/os que sobreviviam eram prontamente açoitadas/os quando chegavam às fazendas de seus senhores; técnicas de tortura que visavam impor cruelmente a hierarquização entre pessoas brancas e negras. Tais técnicas, que se tornaram autenticamente nacionais, foram posteriormente incorporadas durante a ditadura militar brasileira, quando detidas/os adentravam delegacias e casernas. Vê-se que as práticas violentas utilizadas no regime militar têm como legado ações de tempos escravocratas.

Em território brasileiro, africanas/os foram escravizadas/os, desumanizadas/os, estupradas/os, agredidas/os física e simbolicamente, exterminadas/os. Foram vistas/os como objetos sexuais, criminosas/os, ladras/ões, alvos preferenciais de encarceramento. Foram impedidas/os de terem força psicológica para criar um mundo simbólico, uma vez que seu físico, constantemente interpelado por trabalhos árduos e torturas, era levado à exaustão. Foram privadas/os de formarem grupos e laços afetivos, o que era visto como risco de possíveis rebeliões e quilombos, campos de resistência à escravização que reuniam fugitivos das senzalas em territórios brasileiros não habitados ${ }^{28}$. Foram afastadas/os de seu futuro, que em realidade não era seu, mas de seu senhor. Foram frequentemente relembradas/os de sua subalternidade. Foram e, infelizmente, ainda são: há uma herança colonial no Brasil.

Nesse sentido, Pelbart, dialogando com as reflexões de Mbembe, argumenta que nosso nazismo contemporâneo em ascensão pode não ser um 'produto importado'. O ódio e a violência a minorias sociais tiveram início no Brasil colonial, período que precedeu os campos de concentração nazistas. As práticas escravocratas serviram como uma espécie de laboratório biopolítico, em que os corpos eram controlados por meio de técnicas como o impedimento de casamentos mistos, o genocídio, a esterilização compulsória. Indo além, Pelbart expressa que, ainda que a necropolítica de que Mbembe trata seja racializada, há outras dimensões que podem atravessá-la. Logo, LGBTs, mulheres, feministas, indígenas e/ou outras minorias sociais representariam certo devir-negro do mundo na necropolítica tropical, o que demonstra que a matriz colonial sobrevive em tempos atuais.

Diferentemente dos exercícios apenas pertencentes ao biopoder, que faz o regramento social por meio da gestão da vida, a necropolítica investe no controle dos corpos a partir da morte ou do temor de que isso ocorra. No contexto eleitoral, os crimes de ódio a minorias sociais elucidaram tal dimensão da necropolítica, em que assassinatos e agudas agressões físicas visavam demonstrar quais corpos são mais matáveis, quais vidas são menos aceitas. Logo, são práticas de ódio que deixam um aviso a quem descumpre os ideais pró-Bolsonaro. O grupo a que uma vítima de crime de ódio pertence recebe, então, uma espécie de alerta de que sua classe está sendo ferida por não ser bem vista ou não se encaixar nas convenções sociais, seja por orientação sexual, raça, identidade de gênero, posicionamento político. Assim, criam-se certas políticas de medo entre as minorias sociais, de modo que qualquer indivíduo a elas pertencente pode ser o próximo.

A soberania, ressignificada na contemporaneidade, não se encontra mais aglomerada na figura do soberano: este não é mais um enviado de Deus à Terra, conforme as clássicas definições de Foucault sobre essa modalidade de exercício de poder. Embora Bolsonaro pareça ser em alguma medida divinizado quando o chamam de 'mito', a ascensão do presidente e de seu ódio tem respaldo e cumplicidade civis, sendo mais ligada a questões políticas do que religiosas. É em nome dele que a coerção a minorias sociais tem sido feita, 
de modo que não é mais preciso que o próprio soberano puna seus súditos. São estes próprios, acreditando em hierarquizações entre si, que agem para a manutenção da ordem soberana, que inclui a cis-heteronormatividade.

Nesse sentido, o ódio e o controle dos corpos podem vir de qualquer lugar, o que gera determinada sensação de iminente perigo. $\mathrm{O}$ algoz, assim, pode estar infiltrado entre nós, cuja possível presença gera um estado de alerta e temor, de tal maneira que as minorias sociais reestruturam suas formas de ser e estar no mundo para se protegerem. Podemos pensar que o medo do ódio do outro é uma forma simbólica de morte, que regra os comportamentos e expressões das minorias sociais, tirando-lhes a espontaneidade de gesticular, vestir-se, andar e existir subjetivamente. Tratemos dos crimes eleitorais de 2018, das constantes notícias sobre mortes de LGBTs, da saída de um importante militante político gay do país por ter sua vida ameaçada, das declarações preconceituosas de uma ministra que deveria cuidar de políticas públicas em torno dos direitos humanos, da eleição de um presidente como Bolsonaro. Tais acontecimentos não tranquilizam a existência LGBT e formam uma rede que fortalece o ódio LGBTfóbico.

Dito isso, cabe também ponderarmos que a morte nem sempre é o óbito em si. Há diferentes modos de morrer e matar, tanto física quanto simbolicamente. A apreensão gerada em LGBTs nesta atual conjuntura política reflete-se na dúvida de se é possível ir e vir livremente sem ser alvo de discriminação, no medo de ser atacado por modos de vestir-se e expressar-se, na insegurança de andar publicamente de mãos dadas com um(a) parceiro/a, no questionamento de se legalmente direitos de gênero e sexualidade serão perdidos. Há determinado cerceamento da liberdade, que regula os modos de ser e estar no mundo. Simbolicamente, subjetividades vão sendo mortas.

Esse direito de matar, próprio aos exercícios soberanos, que Mbembe e Pelbart abordam em suas discussões necropolíticas parece inibir o que Butler ${ }^{29}$ chama de direito de aparecer. O direito de aparecer é um movimento feito por alguns corpos que reivindicam direta ou indiretamente que não são descartáveis e que são vidas que merecem ser, sim, vividas. Essa reivindicação surge porque algumas vidas não são qualificadas como tal, de forma que não são enlutadas, o que se deve à influência de enquadramentos epistemológicos ${ }^{30}$. Segundo essa lógica, seres sociais são reconhecidos a partir de normas produzidas e repetidas. Antes de se reconhecer alguém, condições de reconhecimento e de precariedade entram em ação. Tais condições colocam as pessoas como dependentes das modelagens sociais, o que as torna essencialmente precárias.

O que acontece é que nem todos são reconhecidos da mesma maneira, tampouco igualmente vistos como vulneráveis: há pessoas que levam vidas tidas como mais precárias que outras, em detrimento de outras. Como corpos sociais, as pessoas têm que contar com o que está fora, inclusive condições que permitem ou não que suas vidas sejam percebidas como importantes e/ou enlutadas, se perdidas. Embora toda vida seja vulnerável e precária, nem toda vida é reconhecida como tal, não à toa tantos grupos socialmente minoritários "sofrem as consequências da deterioração de redes de apoio sociais e econômicos mais do que outro, ficam diferencialmente expostas ao dano, à violência e à morte" ${ }^{30}$, ainda que possam desenvolver habilidades políticas que contornem essa situação. No caso dos LGBTs, há diversos discursos e ações regulatórias e normativas que autoritariamente visam vigiar nossa existência.

Isso se dá porque a LGBTfobia está inserida em um contexto de gênero e sexualidade atravessado por normas. A partir das genitálias de recém-nascidos, expectativas sociais são formadas: um pênis confere o status de homem a um ser; uma vagina, o de uma mulher. Além de articular sexo biológico à identidade de gênero, o imperativo biológico também o faz com relação à orientação sexual ${ }^{31}$, de tal forma que os órgãos chamados de sexuais, geradores da totalidade corporal, são reprodutores e produtores de cisgeneridade e heterossexualidade.

Por essa perspectiva, homens e mulheres teriam características específicas e opostas, mas seriam semelhantes em sua orientação sexual - a heterossexual - para completarem-se. Eles seriam seres racionais, fortes, ativos, violentos, dados às coisas da rua e do sexo; elas seriam seres emocionais, frágeis, passivos, 
pacíficos, dados às coisas do lar e do amor, distinção vista como natural. Essa marcada oposição entre homens e mulheres os concebe como duas identidades fixas universais e antagônicas, cuja relação é constituída pela superioridade masculina ${ }^{32}$.

A respeito da heterossexualidade, Wittig ${ }^{33}$ expressa que ela não é uma instituição, mas um regime político que se baseia na submissão e na apropriação das mulheres. Para a pensadora, vivemos em uma sociedade em que o pensamento heterossexual firma um contrato social, de modo que viver em sociedade consiste em viver em heterossexualidade. Assim sendo, as identidades de gênero não cisgêneras e as orientações sexuais não heterossexuais não apareceriam mais do que de forma fantasmática, como desviantes. Tal visão de Wittig dialoga com o conceito de heteronormatividade de Warner, que entende que a humanidade é tida como sinônimo de heterossexualidade: pertencer a essa categoria é automaticamente pertencer à normalidade. Quem descumpre o contrato cis-heterossexual acaba, assim, por sofrer com ações violentas.

As contribuições teóricas de Butler nos ajudam a contextualizar a existência de corpos cujas vidas são consideradas pouco valiosas em decorrência de sua orientação sexual ou identidade de gênero. A partir do estabelecimento social de condições de precariedade e da hierarquização, os corpos assassinados, feridos e/ou odiados por LGBTfobia não têm sua precariedade reconhecida, assim como lhes é negado o direito de aparecer. Como não estão conformados com ideais de gênero e sexualidade, tais corpos são vistos como descartáveis e/ou matáveis.

O (crime de) ódio LGBTfóbico opera a partir dessa lógica. A ausência de uma lei que criminaliza práticas desse tipo, o despreparo e a indelicadeza policiais ao atender vítimas de discriminações e o direito tácito pró-Bolsonaro de matar/agredir/odiar minorias sociais despontam como questões que podem ser consideradas de um Estado de exceção. Não é todo corpo assassinado e/ou violentado de qualquer maneira que seja que tem o direito de demandar por justiça policial e legal. Parece inocente pensar, pois, que a lei chega para todos, enquanto em realidade ela ancora-se em relações de poder que reconhecem a precariedade de uns em detrimento da de outros. Sugerimos, assim, que as vítimas de (crimes de) ódio LGBTfóbico assim o são pelo funcionamento de um Estado de exceção, que autoriza direta ou indiretamente a violência direcionada a um grupo social específico.

\section{Dilatação da noção de crime de ódio e uma rede de cumplicidade}

Mason, McKay, Maher, McCulloch, Wickes e Pickering ${ }^{10}$ fazem uma análise crítica da noção de crime de ódio, abordando que o conceito está envolto por conflitos e divergências na contemporaneidade ocidental. Para a pesquisadora em criminologia, os significados de crime de ódio estão circunscritos no contexto social, legal e acadêmico em que se inserem. De tal forma, é um desafio, tanto local quanto global, criar um sentido comum sobre esse tipo de crime, o que abriria espaço para que se construíssem práticas e visões compartilhadas entre população, estruturas governamentais, legisladores, entidades policiais e judiciárias. Por meio da compatibilidade conceitual, tais ações criminosas teriam maiores probabilidades de não passarem impunes.

Também apontam os autores que, dentre as diferentes formas de compreender os crimes de ódio, é relevante pontuar alguns elementos que emergem das teorias. Para além de se vincularem ao ódio, tais crimes também passam por motivações preconceituosas e discriminatórias. Entende-se, ademais, que esse tipo de crime não tem como alvo apenas um indivíduo, mas se destina a um grupo específico, ao qual a vítima pertence ou que ela representa. As vítimas, por tal raciocínio, não são significativamente importantes para os agressores. É por esse motivo que se delineia algum tipo de violência simbólica por trás dos crimes de ódio, muitos dos quais considerados enquanto crimes que visam 'dar um recado' a uma população tida como inferior pelos agressores, seja por conta de seu gênero, sua sexualidade, sua raça, sua religião, sua nacionalidade ou outra característica. 
É possível afirmar que crime de ódio LGBTfóbico não é, pois, individual no sentido de que não atinge uma só pessoa. Ele, longe de agredir um corpo isoladamente, deixa um aviso de terror para a população LGBT. Por essa razão, podemos pensar os crimes de ódio enquanto prática necropolítica, na medida em que quem vive, ao tomar conhecimento da morte e/ou agressão de membros de seu grupo social, passa a temer por sua vida e tem suas subjetividades e expressões controladas como técnica de sobrevivência. A regulação dos corpos é feita a partir do medo da morte.

Adicionalmente, estatísticas ${ }^{11}$ demonstram que agressores marcam suas vítimas com múltiplos tiros, facadas ou punhaladas, excedendo a mínima violência necessária para levar um corpo ao óbito. Os crimes de ódio LGBTfóbicos funcionam, pois, como uma espécie de higiene social, em que práticas sexuais e/ou expressões de gênero tidas como dissonantes merecem o extermínio. Ao agirem com vias de atingir certa população, os perpetradores dos crimes intentam a manutenção de hegemonias e de marginalizações, de tal forma que seus atos podem ser lidos enquanto reguladores de hierarquias sociais.

Entendemos também que os crimes de ódio tampouco são individuais no sentido de que não são cometidos por uma só pessoa. Os agressores agem com consciência e com o apoio, direto ou não, de uma rede de cumplicidade. Inspirados pelas reflexões de Borrillo ${ }^{34}$, podemos dizer que a LGBTfobia requer a cumplicidade de um grande número de entidades: sociedade civil; instituições midiáticas, policiais, políticas e jurídicas. Em meio ao contexto supracitado, encontram-se as falas e ações homofóbicas de Bolsonaro e seus eleitores, que fomentam que crimes de ódio a LGBTs e a outras minorias sociais.

A dilatação que nos propomos envolve refletir sobre a noção de crime de ódio não apenas pela perspectiva do Direito legal e jurídico, sobretudo internacional. Temos consciência de que a nomenclatura vem exatamente desse campo de conhecimento, mas sua utilização tem se expandido por militâncias e organizações do terceiro setor, sendo ressignificada. Isso se dá exatamente pelo fato de o Direito nem sempre colaborar para o enfrentamento de grandes violências sofridas por grupos específicos. No caso específico brasileiro, o crime de ódio não se faz presente em nível constitucional, e seus contornos em níveis de jurisprudência nem sempre são evidentes. Quanto aos crimes de ódio direcionados aos LGBTs, a própria ausência de leis nacionais que criminalizem a LGBTfobia compõe o que chamamos aqui de rede de cumplicidade, o que torna mais difícil o reconhecimento do preconceito vivido pelas pessoas desse grupo.

Sabemos da importância de leis que prevejam ações que envolvem crimes a LGBTs, bem como julgamentos que responsabilizem criminosos: essas instâncias possuem caráter institucionalmente legitimador no cenário contemporâneo ocidental. Contudo, a existência e a aplicabilidade das leis estão cercadas por falhas e não necessariamente trazem mudanças positivas radicais, mesmo que os crimes de ódio tornem-se uma categoria legal e jurídica. Como expressa Mendonça, "[m]esmo quando o processo legislativo reconhece, diante da reivindicações sociais por direitos e igualdade, a obsolescência de algumas leis, revogando-as e propondo leis adequadas aos novos tempos e às novas configurações sociais, as normas antigas que as estimularam permanecem em funcionamento graças as operações próprias de certos conjuntos de regras e de costumes"12.

Envolvidas por normas e regras que perduram temporalmente, contextos socioculturais continuam tendo hierarquias como engrenagens, a incluir as articulações entre heteronormatividade e LGBTfobia. Convém, assim, tensionar epistemologicamente a noção de crime de ódio de tal maneira que identifiquemos, para além de casos criminosos isolados, como o ódio articula-se àquelas engrenagens e às dinâmicas sociais, disseminando-se entre nós.

Berenice Bento, em sua conferência no III Congresso de Diversidade Sexual e de Gênero de 2018, defende que o ódio que se expressa no contexto político não é novo: a crítica ao kit anti-homofobia e sua demonização como se fosse um material que sexualiza as crianças e promove a pedofilia; a criação da Escola Sem Partido como modo de evitar que ‘o comunismo’ se propague pelo Brasil; a difusão da ideia de que há uma 'ideologia de gênero', a qual visaria desmantelar os valores morais, éticos e familiares nacionais; as múltiplas declarações de Bolsonaro que já foram mencionadas, principalmente se pensarmos que elas vêm 
de um atual presidente. Ainda quando candidato e agora como líder do Executivo, Bolsonaro personifica a necropolítica tropical, que na contemporaneidade mostra sua face sem qualquer véu para encobri-la. Se colocarmos em perspectiva as manifestações de ódio diacronicamente, desde as coloniais até as mais recentes, perceberemos que a vitória de Bolsonaro não era tão imprevisível assim. As manifestações conservadoras e preconceituosas brasileiras que valorizam algumas vidas em detrimento de outras estiveram historicamente, em menor ou maior grau, diante de nós. Essa é a necropolítica tropical.

Éa partir da intersecção entre numerosas manifestações de ódio que os crimes de ódio são potencializados: atos criminosos se dariam a partir da cumplicidade de um grande número de pessoas e instituições, embora suas mãos não necessariamente tenham tocado as vítimas. Com essas considerações, reforçamos que encontrar um responsável por crimes de ódio não resolve de modo efetivo a problemática do ódio como algo difuso, de tal modo que pensá-los apenas como categoria do Direito se mostra insuficiente. Em nível geral, crimes de ódio aparecem como quaisquer ameaças, agressões físicas/morais/psicológicas, torturas ou assassinatos destinados a grupos específicos, bem como o combate para que seus direitos e políticas públicas não avancem. Acreditamos, deslocando o conceito, que há maneiras mais sofisticadas e simbólicas de praticar tais crimes ou incentivá-los, desde eleger um presidente LGBTfóbico até flexibilizar suas agressivas falas como se elas não fossem repercutir em violências futuras.

\section{Considerações finais}

O desejo de que as minorias sociais morram ou a vontade de matá-las, seja simbolicamente ou não, se manifestam a partir do legado que carregamos, que envolve o genocídio indígena e a escravização de negros. Matáveis, as minorias sociais na contemporaneidade brasileira transitam do espaço da exclusão para o do extermínio, como explica Santos ${ }^{35}$. Por não serem consideradas cidadãs de bem - categoria restrita principalmente a homens heterossexuais brancos, viris e de classes não populares - tais pessoas são vistas como ameaças ou atrasos para o funcionamento da nação. Logo, suas vidas importam menos. E é desse modo que Bolsonaro e parte significativa de seu eleitorado discursam, defendendo que 'bandido bom é bandido morto' e vibrando com a violência que atinge corpos vistos como dissonantes.

Encontram-se nas minorias sociais os LGBTs, que são alvo de preconceito em decorrência da cisheteronormatividade, que pune aqueles que escapam às normas de gênero e sexualidade. Tal população, vivente em tempos pró-Bolsonaro no Brasil, é atingida por crimes de ódio, cuja manifestação tem sido autorizada a partir de um Estado de exceção. Esse tipo de crime não atinge um corpo isoladamente. Contrariamente, visa gerar políticas de terror para que pessoas pertencentes ao grupo atacado tenham suas subjetividades silenciadas. A partir do deslocamento teórico e político de crime de ódio, reivindicamos que a LGBTfobia liga-se não somente ao óbito e/ou à agressão física, mas uma rede de cumplicidade que encoraja que o ódio contra os LGBTs se perpetue de diferentes formas. Na necropolítica tropical, os corpos são controlados pela morte ou pelo medo de que ela ocorra, morte que se espelha tanto em assassinatos quanto no regramento dos modos de ser e estar no mundo que destoam das convenções sociais.

Ao ampliarmos a noção de crime de ódio e vê-la enquanto uma rede de cumplicidade, lançamos luz sobre práticas LGBTfóbicas por vezes taxadas como meras brincadeiras ou como discursos que não se convertem em práticas discriminatórias. No atual quadro político brasileiro, em que avança o conservadorismo, é preciso enfrentar desafios de distintas ordens e pensar em exercícios epistemológicos, práticos, militantes e/ou rotineiros para resistir, existir e lutar pelo reconhecimento LGBT. 


\section{Referências}

1. Sodré M. Por um conceito de minoria. In: Paiva R; Barbalho A, organizadores. Comunicação e cultura das minorias. São Paulo: Paulus, 2005. p.11-14.

2. Ramalho R. Bolsonaro vira réu por falar que Maria do Rosário não merece ser estuprada [Internet] G1 (Globo Comunicação e Participações S.A.). 2016 jun. [citado em 2019 fev. 08]:Política. Disponível em: http://g1.globo.com/politica/noticia/2016/06/bolsonaro-vira-reu-por-falar-que-maria-do-rosario-naomerece-ser-estuprada.html.

3. AFP. Frases polêmicas do candidato Jair Bolsonaro. [Internet] Exame (Abril). 2018 set. [citado em 2019 fev. 08]:Brasil. Disponível em: https://exame.abril.com.br/brasil/frases-polemicas-do-candidato-jairbolsonaro/.

4. Redação. Bolsonaro: "Eu tenho 5 filhos. Foram 4 homens, a quinta eu dei uma fraquejada e veio uma mulher" [Internet]. Revista Fórum. 2017 abr. [citado em 2019 fev. 08]:Política. Disponível em: https://www.revistaforum.com.br/bolsonaro-eu-tenho-5-filhos-foram-4-homens-a-quinta-eu-dei-umafraquejada-e-veio-uma-mulher-3/.

5. Cipriani J. Veja 10 frases polêmicas de Bolsonaro que o deputado considerou 'brincadeira' [Internte]. Estado de Minas (Jornal Estado de Minas). 2018 abr. [citado em 2019 fev. 08]:Política. Disponível em: https://www.em.com.br/app/noticia/politica/2018/04/14/interna_politica, 951685/10-frases-polemicasde-bolsonaro-que-o-deputado-considerou-brincadeira.shtml.

6. Redação. "Esses marginais vermelhos serão banidos de nossa pátria", diz Bolsonaro [Internet]. Veja (Abril). 2018 out. [citado em 2019 fev. 08]:Brasil. Disponível em: https://veja.abril.com.br/brasil/essesmarginais-vermelhos-serao-banidos-de-nossa-patria-diz-bolsonaro/.

7. Thomaz D. "Acho bom ter segundo turno para bater mais na esquerda", diz ativista político gay [Internet]. Época (Globo Comunicação e Participações S.A.). 2018 out. [citado em 2019 fev. 08]:Política. Disponível em: https://epoca.globo.com/acho-bom-ter-segundo-turno-para-bater-mais-na-esquerda-dizativista-politico-gay-23139651.

8. Carta Capital. Bolsonaro em 25 frases polêmicas [Internet]. Carta Capital (Editora Confiança). 2018 out. [citado em 2019 fev. 08]: Política. Disponível em: https://www.cartacapital.com.br/ politica/bolsonaroem-25-frases-polemicas/.

9. Brasil L. "Próximo passo será legalizar a pedofilia", diz Bolsonaro [Internet]. Estado de Minas (Jornal Estado de Minas). 2011 mai 07. [citado em 2019 fev. 08]:Política. Disponível em: https://www.em.com. br/app/noticia/politica/2011/05/07/interna_politica,226082/proximo-passo-sera-legalizar-a-pedofilia-dizbolsonaro.shtml.

10. Mason, G; McKay C; Maher J; McCulloch J; Wickes R; Pickering S. Policing Hate Crime: Understanding Communities and Prejudice, Routledge: London; 2017.

11. Comissão Interamericana de Direitos Humanos. Violência contra Pessoas Lésbicas, Gays, Bissexuais, Trans e Intersexo nas Américas. Washington: A Comissão [Internet]. 2015. [citado em 2019 fev. 08]. Disponível em: http://www.oas.org/pt/cidh/docs/pdf/ViolenciaPessoasLGBTI.pdf.

12. Mendonça $\mathrm{C}$. Heteronormatividade: breves apontamentos sobre a força das leis, das normas e das regras nos processos de assujeitamento. In: Gonçalves J; Trindade V; Machado F, editors. Dar-se a ver: textualidades, gêneros e sexualidades em estudos da comunicação. Belo Horizonte: PPGCOM UFMG; 2018. p.14-21.

13. Warner M. Fear of a Queer Planet: queer politics and social theory. Minneapolis: University of Minnesota Press; 1994.

14. Jimenez R; Sinues O. Los géneros de la violência. Madrid: Editorial Egales; 2010.

15. Joven Pan. Instituiç̃̃es de ensino são pichadas com frases preconceituosas em todo Brasil [Internet]. Joven Pan (Portal Jovem Pan Online). 2018 out. [citado em 2019 fev. 08]:Política. Disponível em: https://jovempan.uol.com.br/eleicoes-2018/presidenciais/instituicoes-de-ensino-sao-pichadas-comfrases-preconceituosas-em-todo-brasil.html.

16. Redação Veja São Paulo. Em vídeo registrado no metrô, grupo canta que "Bolsonaro vai matar veado"[Internet]. Veja São Paulo (Abril). 2018 out. [citado em 2019 fev. 08]: Política. Disponível em: https://vejasp.abril.com.br/cidades/matar-viado-bolsonaro-homofobicos-metro/. 
17. Folha Press. Polícia de MG investiga morte com suspeita homofóbica e política [Internet]. Msn (Microsoft News). 2018 nov. [citado em 2019 fev. 08]:Política. Disponível em: https://www.msn.com/pt-br/noticias/ brasil/pol\%C3\%ADcia-de-mg-investiga-morte-com-suspeita-homof\%C3\%B3bica-e-pol\%C3\%ADtica/arBBPbTpx?ocid=sf.

18. Cruz MT. Travesti é assassinada no centro de SP sob gritos de 'Bolsonaro presidente' [Internet]. Ponte (Ponte Jornalismo). 2018 out. [citado em 2019 fev. 08]. Disponível em: https://ponte.org/travesti-eassassinada-a-facadas-no-centro-de-sp-sob-gritos-de-bolsonaro-presidentel.

19. Grupo Gay da Bahia. População LGBT morta no Brasil. Grupo Gay da Bahia [Internet]. 2019. [citado em 2019 fev. 08]. Disponível em: https://grupogaydabahia.files.wordpress.com/2019/01/ relat\%C3\%B3riode-crimes-contra-lgbt-brasil-2018-grupo-gay-da-bahia.pdf.

20. Redação Lado A. Vídeo: Damares diz que gays querem banir a Bíblia no Brasil [Internet]. Revista Lado A (Lado A Comunicações). 2019 jan 16. [citado em 2019 fev. 08]. Disponível em: https://revistaladoa.com. br/2019/01/noticias/video-damares-diz-que-gays-querem-banir-a-biblia-no-brasil/.

21. Dimenstein G. Dimenstein: Damares diz que sexo entre mulheres é uma "aberração" [Internet]. Catraca Livre. 2019 jan 01. [citado em 2019 fev. 08]: Política. Disponível em: https://catracalivre. com.br/ parceiros-catraca/dimenstein/dimenstein-damares-diz-que-sexo-entre-mulheres-e-uma-aberracao/.

22. AFP. Damares Alves propõe meninos de azul e meninas de rosa para 'nova era' no Brasil [Internet]. Isto é (Editora Três). 2019 jan. [citado em 2019 fev. 08]:Política. Disponível em: https://istoe.com.br / damares-alves-propoe-meninos-de-azul-e-meninas-de-rosa-para-nova-era-no-brasil/.

23. Pelbart P. Necropolítica tropical: fragmentos de um pesadelo em curso. Série Pandemia. São Paulo: N-1 Edições; 2018.

24. Mbembe A. Necropolítica. Sta. Cruz de Tenerife: Melusina; 2011.

25. Foucault M. Vigiar e punir: nascimento da prisão. Petrópolis: Vozes; 2002.

26. Foucault M. Em defesa da sociedade: curso no Collège de France. São Paulo: Martins Fontes; 1999.

27. Souza D; Passos A. Soberania, disciplina e biopoder: dimensões da analítica do poder em Michel Foucault. Cadernos Zygmunt Bauman. 2013;3(5):62-81.

28. Munanga K. Origem e histórico do quilombo na África. Revista USP. 1996;28:56-63.

29. Butler J. Corpos em aliança e a política das ruas. Rio de Janeiro: Civilização Brasileira; 2018.

30. Butler J. Quadros de guerra: quando a vida é passível de luto?. Rio de Janeiro: Civilização Brasileira; 2015.

31. Butler J. Problemas de gênero: feminismo e subversão da identidade. Rio de janeiro: Civilização Brasileira; 2017.

32. Banditer E. XY la identidade masculina. Madrid: Alianza Editorial; 1993.

33. Wittig M. El pensamiento heterossexual y otros ensayos. Barcelona: Editorial Egales; 2016.

34. Borrillo D. Homofobia: história e crítica de um preconceito. Belo Horizonte: Autêntica Editora; 2010.

35. Santos LG. Viva a morte!. Série Pandemia. São Paulo: N-1 Edições; 2018. 